\title{
Association of Age With Lower Urinary Tract Function in Adult Men Presenting for Urodynamics: A Database Analysis
}

\author{
Sanjay Sinha, ${ }^{\mathbb{L}}$ Lavina Matai \\ Department of Urology, Apollo Hospitals, Hyderabad, India
}

\begin{abstract}
Background Knowledge regarding lower urinary tract function in adult men could help in making informed choices. Few studies have examined the entire spectrum of adult males.

Methods This is a retrospective analysis of all adult men with refractory non-neurogenic urinary symptoms presenting to a tertiary center over 9 years. International Continence Society defined indices bladder outlet obstruction index (BOOI) and bladder contractility index (BCI) were calculated with established classification. Storage abnormality was defined as presence of detrusor overactivity, poor compliance $\left(<20 \mathrm{~mL}\right.$ per $\left.\mathrm{cm} \mathrm{H}_{2} 0\right)$ or both. Data were analyzed by non-parametric tests using SPSS (version 20.0.0, Armonk NY $)(P<0.05$ significant; 2-tailed). Where appropriate, correction for multiple hypothesis testing was applied.

Results A total of 1596 men (range 18 to 91 years, median 51.0 years; IQR 34 to 64 years) were eligible. Median BCI and BOOI were 99.5 and 37.0, respectively, and a storage abnormality was noted in $41.7 \%$. On multivariate analysis, age was significantly associated with urodynamic findings. While not strictly linear, for each 10 years increase in age, on average, the BCI fell 2.4 points and the BOOI increased by 2.4 points. Increasing age was also associated with increasing odds of finding a storage abnormality (OR 1.015; 95\%CI 1.008 to $1.022 ; P<0.001$ ). On post hoc analysis (Bonferroni correction), men under 30 years were least likely of any group to show obstruction (30.3\%; median BOOI 26).
\end{abstract}

Conclusions Adult men with refractory urinary symptoms show age-associated differences in urodynamic findings. An awareness of these trends can help take more informed decisions in clinical care.

\section{Introduction}

Age is known to impact all aspects of lower urinary tract function[1]. Knowledge regarding detrusor contractility, outlet obstruction and storage abnormality in men of different age groups could help in making more informed choices with regard to evaluation and treatment. Men with an underactive detrusor or severe storage abnormality show an inferior outcome following prostate surgery[2,3]. The European Association of Urology guidelines recommends invasive urodynamics testing before surgery in specified age groups[4]. However, few large studies have examined the entire spectrum of adult males, with most excluding either the young or the elderly.

\section{Key Words}

Urodynamics, aging, bladder outlet obstruction, bladder contractilty, detrusor overactivity, bladder compliance

\section{Competing Interests}

None declared.

\section{Article Information}

Received on March 31, 2021

Accepted on June 5, 2021

Soc Int Urol J.2021;2(5):274-281

DOl: https://10.48083/LQXF2741 


\section{Abbreviations}

$\mathrm{BCI}$ bladder contractility index

B00I bladder outlet obstruction index

Cl confidence interval

IQR interquartile range

OR odds ratio

PVR post-void residual

This is a retrospective database analysis of all adult men who presented for urodynamics with a non-neurogenic lower urinary tract abnormality to a large volume referral center.

\section{Material and Methods}

Data pertaining to all adult men with a non-neurogenic lower urinary tract condition who underwent urodynamics over the last 9 years (May 2011 to February 2020) were retrieved. Ethics committee approval was obtained (AHH-ACD-001-01-20). Exclusion criteria included prior surgery of the lower urinary tract, history of indwelling catheter or intermittent catheterization, another lower urinary tract pathology such as posterior urethral valves or reflux, neurological disease, and primary upper urinary tract pathology such as ureteropelvic junction obstruction or urolithiasis (except in men with incidental non-obstructive calyceal stones); also excluded were men in whom a voiding phase evaluation was not feasible (for instance due to severe storage abnormality precluding filling) and those for whom we had incomplete data.

Urodynamics was performed as per International Continence Society (ICS) recommendations[5] using a two-catheter technique (both 5F). The peak detrusor contraction pressure of the tallest DO was recorded as the DO pressure. Compliance was measured from the commencement to the end of filling phase. The end fill detrusor pressure was recorded as $1 \mathrm{~cm} \mathrm{H}_{2} 0$ whenever it was ' 0 '. Graphs were manually scrutinized to eliminate artifacts. When a patient produced a volitional contraction but failed to void, the maximum detrusor pressure $\left(\mathrm{P}_{\mathrm{det} \cdot \max }\right)$ was recorded in place of $\mathrm{P}_{\mathrm{det} \cdot \mathrm{Qmax}}$. Bladder outlet obstruction index (BOOI) and bladder contractility index (BCI) were calculated as per ICS guidelines[6]. For patients with a calculated BOOI of $\leq$ 0 , a value of 0 was recorded. The BOOI and BCI were both recorded as ' 0 ' in men with acontractility. BCI was categorized as 0 (underactive, $<100$ ), 1 (normal, 100 to 150 ) and 2 (strong, $\geq 150$ ). BOOI was categorized as 0 (unobstructed, <20), 1 (equivocal obstruction, 20 to 40 ) and 2 (unequivocally obstructed, $\geq 40$ ). In the occasional patient who voided more than the volume filled, the post-void residual (PVR) was recorded as $0 \mathrm{~mL}$.
Non-parametric tests were used since the data were not normally distributed on preliminary analysis. SPSS (version 20.0.0, Armonk NY) was used for analysis. The data were first analyzed by stratifying age into "age by decade" to assess the impact on different urodynamics outcome measures. Post hoc analyses were performed for the categories of the 3 main urodynamic findings BCI, BOOI, and storage abnormality. Multivariate analysis was performed to assess the independent impact of age (un-stratified) on the numerical value of BCI and BOOI, as well as the presence of storage abnormality. Data for linear regression were presented as estimate of change in dependent variable with each unit change in independent variable with $95 \%$ confidence intervals (CI) and $P$-value.

\section{Results}

A total of 3980 adult men with non-neurogenic lower urinary tract dysfunction underwent urodynamics between May 2011 and February 2020. After exclusions (indwelling or intermittent catheterization, 1629; prior urinary tract surgery, 264; dialysis or transplantation, 97; history of congenital lower urinary tract disorder, 49; voiding phase evaluation not feasible, 20 ; incomplete data, 325), there were 1596 (range 18 to 91 years, median 51.0 years; IQR 34 to 64 years) evaluable patients.

Urodynamic findings stratified by "age by decade" along with univariate analyses are shown in Table 1. Presence of detrusor overactivity, abnormal storage, and diabetes mellitus, as well as capacity, median BOOI, BOOI category, BCI category, $\mathrm{P}_{\mathrm{det} \cdot \mathrm{Qmax}}, \mathrm{Q}_{\max }$, and PVR, all showed a significant association with age. Detrusor overactivity was noted in 524 patients $(32.8 \%)$ with median peak detrusor pressure $33 \mathrm{~cm} \mathrm{H}_{2} 0$ (IQR 20 to 55). A total of $17.2 \%$ of men presented with hydronephrosis of at least one kidney.

Numerical value of BCI and BOOI stratified by "age by decade" and pressure-flow data are depicted in Figures 1 to 3. Intergroup post hoc analysis (crosstab chi-square; Bonferroni correction) for association of "age by decade" with storage abnormality is shown in Table 2 .

Overall, the commonest major urodynamics finding was an underactive detrusor $(\mathrm{BCI}<100)$, noted in 834 men (52.3\%). Unequivocal bladder outlet obstruction (BOOI $\geq 40$ ) was noted in 725 men (45.4\%). Abnormal storage was seen in 665 men (41.7\%). Isolated obstruction, isolated underactivity, and isolated storage abnormality were noted in $14.2 \%, 26.8 \%$, and $5.4 \%$, respectively.

Multiple regression analyses were performed to assess the impact of age on BOOI, BCI, and presence of storage abnormality. The overall models to predict BOOI, BCI, and storage abnormality were statistically 


\section{TABLE 1.}

Urodynamic findings based on "age by decade" along with univariate analyses in adult men with refractory lower tract symptoms

\begin{tabular}{|c|c|c|c|c|c|c|c|c|c|} 
& Overall & $\begin{array}{c}<30 \\
\text { years }\end{array}$ & $\begin{array}{c}30-40 \\
\text { years }\end{array}$ & $\begin{array}{c}40-50 \\
\text { years }\end{array}$ & $\begin{array}{c}50-60 \\
\text { years }\end{array}$ & $\begin{array}{c}60-70 \\
\text { years }\end{array}$ & $\begin{array}{c}70-80 \\
\text { years }\end{array}$ & $\begin{array}{c}>80 \\
\text { years }\end{array}$ & Statistic \\
\hline $\mathbf{n}$ & 1596 & 317 & 242 & 226 & 290 & 317 & 176 & 28 & \\
\hline
\end{tabular}

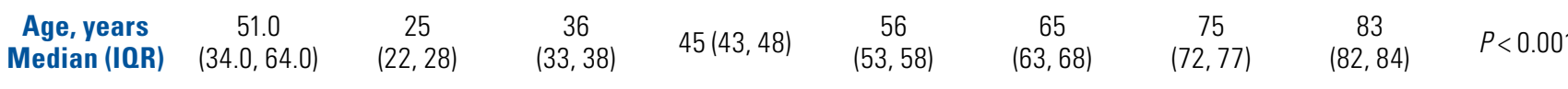

\begin{tabular}{|c|c|c|c|c|c|c|c|c|c|c|}
\hline \multicolumn{2}{|c|}{ DM (\%) } & $\begin{array}{c}498 \\
(31.2)\end{array}$ & $\begin{array}{c}5 \\
(1.6)\end{array}$ & $\begin{array}{c}16 \\
(6.6)\end{array}$ & $\begin{array}{c}48 \\
(21.2)\end{array}$ & $\begin{array}{c}137 \\
(47.4)\end{array}$ & $\begin{array}{c}176 \\
(55.5)\end{array}$ & $\begin{array}{c}98 \\
(55.7)\end{array}$ & $\begin{array}{c}18 \\
(64.3)\end{array}$ & $P<0.001$ \\
\hline \multicolumn{2}{|c|}{$\begin{array}{l}\text { Detrusor } \\
\text { overactivity } \\
(\%)\end{array}$} & $\begin{array}{c}524 \\
(32.8 \%)\end{array}$ & $\begin{array}{c}84 \\
(26.5)\end{array}$ & $\begin{array}{c}66 \\
(27.3)\end{array}$ & $\begin{array}{c}58 \\
(25.7)\end{array}$ & $\begin{array}{c}79 \\
(27.2)\end{array}$ & $\begin{array}{c}131 \\
(41.3)\end{array}$ & $\begin{array}{c}96 \\
(54.5)\end{array}$ & $\begin{array}{c}10 \\
(35.7)\end{array}$ & $P<0.001$ \\
\hline \multirow{3}{*}{ 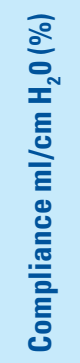 } & $<10$ & $\begin{array}{l}118 \\
(7.4)\end{array}$ & $\begin{array}{l}25 \\
(7.9)\end{array}$ & $\begin{array}{c}19 \\
(7.9)\end{array}$ & $\begin{array}{c}13 \\
(5.8)\end{array}$ & $\begin{array}{l}23 \\
(7.9)\end{array}$ & $\begin{array}{c}20 \\
(6.3)\end{array}$ & $\begin{array}{c}14 \\
(8.0)\end{array}$ & $\begin{array}{c}4 \\
(14.3)\end{array}$ & \multirow{3}{*}{$P=0.092$} \\
\hline & $10-20$ & $\begin{array}{c}186 \\
(11.7)\end{array}$ & $\begin{array}{c}41 \\
(12.9)\end{array}$ & $\begin{array}{c}32 \\
(13.2)\end{array}$ & $\begin{array}{c}17 \\
(7.5)\end{array}$ & $\begin{array}{c}24 \\
(8.3)\end{array}$ & $\begin{array}{c}47 \\
(14.8)\end{array}$ & $\begin{array}{c}20 \\
(11.4)\end{array}$ & $\begin{array}{c}5 \\
(17.9)\end{array}$ & \\
\hline & $\geq 20$ & $\begin{array}{l}1292 \\
(81.0)\end{array}$ & $\begin{array}{l}251 \\
(79.2)\end{array}$ & $\begin{array}{c}191 \\
(78.9)\end{array}$ & $\begin{array}{c}196 \\
(86.7)\end{array}$ & $\begin{array}{c}243 \\
(83.8)\end{array}$ & $\begin{array}{c}250 \\
(78.9)\end{array}$ & $\begin{array}{c}142 \\
(80.7)\end{array}$ & $\begin{array}{c}19 \\
(67.9)\end{array}$ & \\
\hline \multicolumn{2}{|c|}{$\begin{array}{c}\text { Abnormal } \\
\text { storage (\%) }\end{array}$} & $\begin{array}{c}665 \\
(41.7 \%)\end{array}$ & $\begin{array}{c}119 \\
(37.5)\end{array}$ & $\begin{array}{c}94 \\
(38.8)\end{array}$ & $\begin{array}{c}71 \\
(31.4)\end{array}$ & $\begin{array}{c}102 \\
(35.2)\end{array}$ & $\begin{array}{c}154 \\
(48.6)\end{array}$ & $\begin{array}{c}108 \\
(61.4)\end{array}$ & $\begin{array}{c}17 \\
(60.7)\end{array}$ & $P<0.001$ \\
\hline \multicolumn{2}{|c|}{$\begin{array}{l}\text { Capacity } \\
\text { (IOR) }\end{array}$} & $\begin{array}{c}320 \\
(301,377)\end{array}$ & $\begin{array}{c}317 \\
(303,361)\end{array}$ & $\begin{array}{c}333 \\
(304,398)\end{array}$ & $\begin{array}{c}331 \\
(304,404)\end{array}$ & $\begin{array}{c}330 \\
(302,392)\end{array}$ & $\begin{array}{c}314(266, \\
366)\end{array}$ & $\begin{array}{c}301 \\
(206,325)\end{array}$ & $\begin{array}{c}303 \\
(197,318)\end{array}$ & $P<0.001$ \\
\hline \multicolumn{2}{|c|}{$\begin{array}{l}\text { EFP } \\
\text { (IOR) }\end{array}$} & $\begin{array}{c}6 \\
(3,13)\end{array}$ & $\begin{array}{c}7 \\
(3,14)\end{array}$ & $\begin{array}{c}7 \\
(3,13)\end{array}$ & $\begin{array}{c}6 \\
(3,11)\end{array}$ & $\begin{array}{c}6 \\
(3,12)\end{array}$ & $\begin{array}{c}6 \\
(3,13)\end{array}$ & $\begin{array}{c}6 \\
(3,10)\end{array}$ & $\begin{array}{c}7 \\
(4,22)\end{array}$ & $P=0.256$ \\
\hline \multicolumn{2}{|c|}{$\begin{array}{l}\mathrm{BCI} \\
\text { (IOR) }\end{array}$} & $\begin{array}{c}98.5 \\
(75.8,128.0)\end{array}$ & $\begin{array}{c}95 \\
(74,130)\end{array}$ & $\begin{array}{c}100 \\
(78,130)\end{array}$ & $\begin{array}{c}98 \\
(70,131)\end{array}$ & $\begin{array}{c}102 \\
(76,133)\end{array}$ & $\begin{array}{c}100 \\
(80,122)\end{array}$ & $\begin{array}{c}96 \\
(79,115)\end{array}$ & $\begin{array}{c}87 \\
(76,108)\end{array}$ & $P=0.356$ \\
\hline \multicolumn{2}{|c|}{$\begin{array}{l}\text { BOOI } \\
\text { (IOR) }\end{array}$} & $\begin{array}{c}37.0 \\
(18.0,64.0)\end{array}$ & $\begin{array}{c}26 \\
(11,46)\end{array}$ & $\begin{array}{c}35 \\
(18,63)\end{array}$ & $\begin{array}{c}36 \\
(17,66)\end{array}$ & $\begin{array}{c}42 \\
(23,77)\end{array}$ & $\begin{array}{c}42 \\
(24,66)\end{array}$ & $\begin{array}{c}41 \\
(23,63)\end{array}$ & $\begin{array}{c}41 \\
(19,57)\end{array}$ & $P<0.001$ \\
\hline \multicolumn{2}{|c|}{$\mathbf{P}_{\text {det }-0 \max } \mathbf{b}$} & $\begin{array}{c}53 \\
(39,78)\end{array}$ & $\begin{array}{c}46 \\
(35,65)\end{array}$ & $\begin{array}{c}52 \\
(39,78)\end{array}$ & $\begin{array}{c}50 \\
(35,83)\end{array}$ & $\begin{array}{c}58 \\
(39,91)\end{array}$ & $\begin{array}{c}60 \\
(41,78)\end{array}$ & $\begin{array}{c}56 \\
(44,74)\end{array}$ & $\begin{array}{c}52 \\
(39,65)\end{array}$ & $P<0.001$ \\
\hline \multicolumn{2}{|c|}{$\mathbf{0}_{\max }$} & $\begin{array}{c}7 \\
(4,10)\end{array}$ & $\begin{array}{c}8 \\
(5,12)\end{array}$ & $\begin{array}{c}7 \\
(4,11)\end{array}$ & $\begin{array}{c}7 \\
(4,10)\end{array}$ & $\begin{array}{c}7 \\
(3,9)\end{array}$ & $\begin{array}{c}7 \\
(4,10)\end{array}$ & $\begin{array}{c}7 \\
(4,10)\end{array}$ & $\begin{array}{c}7 \\
(4,9)\end{array}$ & $P<0.01$ \\
\hline \multicolumn{2}{|c|}{ PVR } & $\begin{array}{c}55 \\
(3,166)\end{array}$ & $\begin{array}{c}22 \\
(0,122)\end{array}$ & $\begin{array}{c}44 \\
(1,168)\end{array}$ & $\begin{array}{c}48 \\
(2,158)\end{array}$ & $\begin{array}{c}79 \\
(7,191)\end{array}$ & $\begin{array}{c}68 \\
(6,184)\end{array}$ & $\begin{array}{c}63 \\
(15,164)\end{array}$ & $\begin{array}{c}107 \\
(33,144)\end{array}$ & $P<0.001$ \\
\hline
\end{tabular}

a Abnormal storage was defined as either presence of detrusor overactivity or compliance $<20 \mathrm{~mL} / \mathrm{cm} \mathrm{H}_{2} \mathrm{O}$ or both.

${ }^{b}$ For patients who could not void, the $P_{\text {det } m \text { max }}$ was recorded instead of $P_{\text {det }}$-amax

EFP End fill pressure; $P_{\text {det:-amax }}$ : detrusor pressure at maximum flow; $Q_{\text {max }}$ : maximum flow rate. 


\section{FIGURE 1.}

Bladder contractility index values stratified by age in box plot

A value over 100 is regarded as normal (horizontal marker line). Note the trend of lower values for median $\mathrm{BCl}$ with each advancing decade beyond the sixth decade.

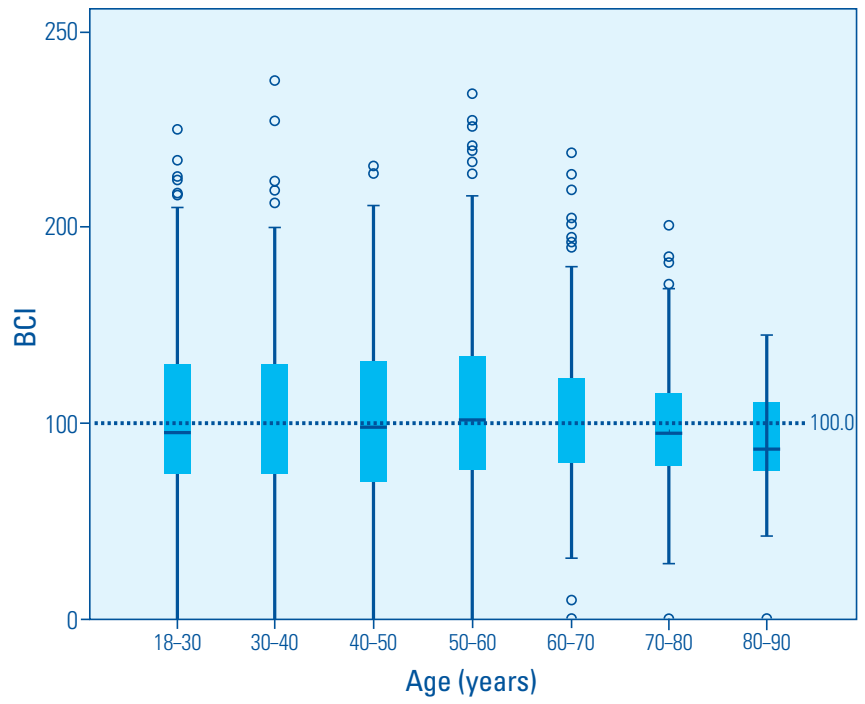

FIGURE 2.

Bladder outlet obstruction index values stratified by age in box plot

A value under 20 is regarded as unobstructed (horizontal marker line). Note the numerically lower median BOOI in men in the 18 to 30 years age group. Intergroup analysis showed that men in the 18 to 30 age group were least likely to show severe obstruction $(P<0.05$; Bonferroni correction).

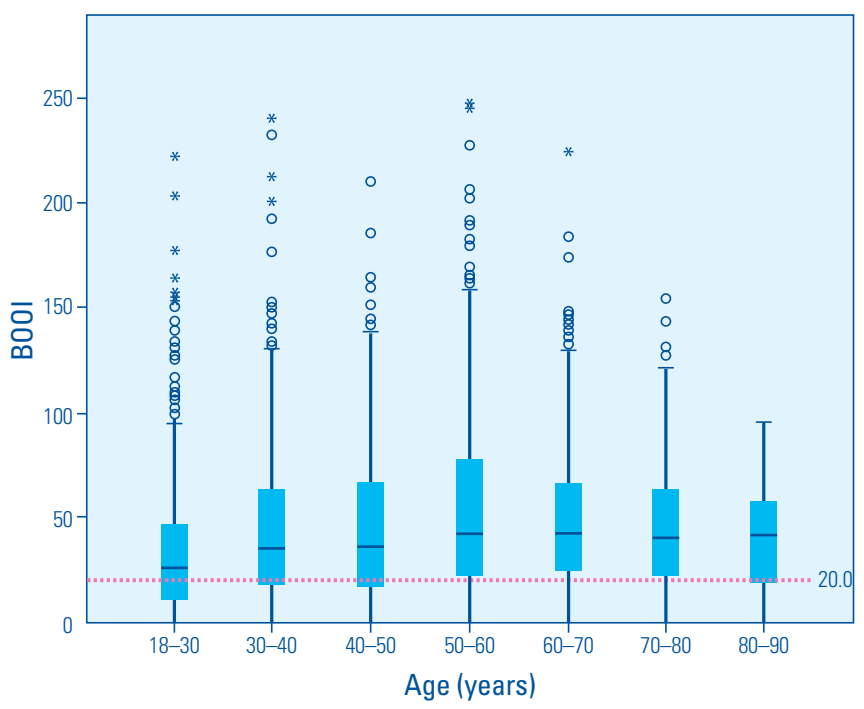

\section{FIGURE 3.}

Scatter plot of $\mathrm{Q}_{\max }$ versus $\mathrm{P}_{\text {det }}$. max

The median value for $\mathrm{Q}_{\max }(7.0 \mathrm{~mL}$ per second) and median $P_{\text {det. }}$ max $\left(53 \mathrm{~cm} \mathrm{H}_{2} 0\right)$ are marked by the horizontal and vertical marker lines, respectively.

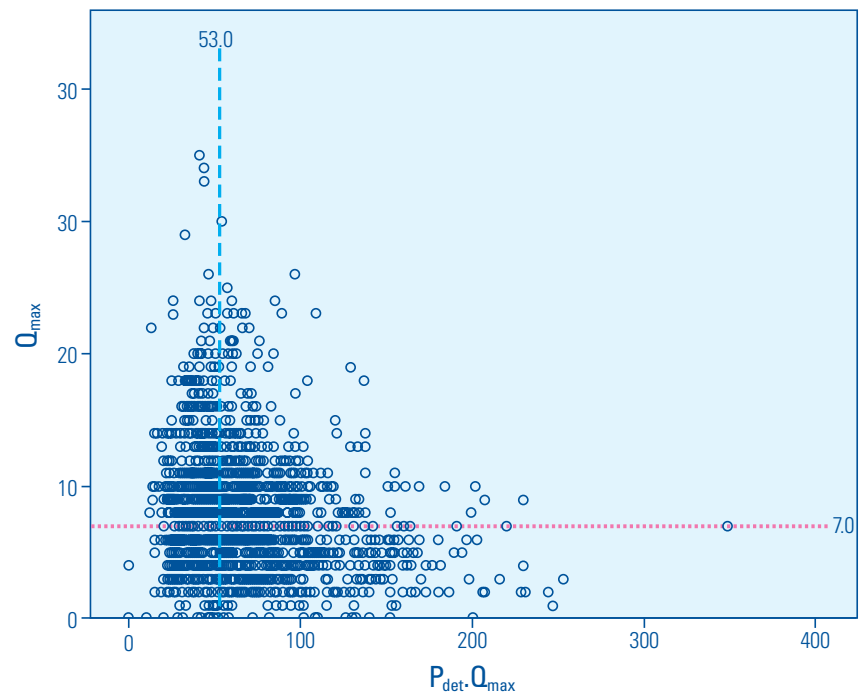

significant. Increasing age was associated with a higher BOOI and presence of storage abnormality but a lower BCI. Age $(-0.240,95 \% \mathrm{CI}-0.352$ to $-0.127 ; P<0.001)$ and BOOI $(0.807 ; 95 \%$ CI 0.765 to $0.849 ; P<0.001)$ but not presence of diabetes mellitus or storage abnormality was associated with BCI. Age $(0.241 ; 95 \%$ CI 0.146 to $0.337 ; P<0.001)$, BCI $(0.582$; $95 \%$ CI 0.552 to 0.613 ; $P<$ $0.001)$ and storage abnormality $(10.887 ; 95 \%$ CI 7.869 to 13.905; $P<0.001$ ) but not diabetes mellitus was associated with BOOI. Age (OR 1.015; 95\%CI 1.008 to 1.022; $P<0.001$ ) and BOOI (OR 1.012; 95\%CI 1.009 to $1.016 ; P$ $<0.001$ ), but not diabetes or BCI, were associated with presence of storage symptoms.

\section{Discussion}

This study showed significant age-associated differences on urodynamics evaluation of men presenting with refractory lower urinary tract symptoms. Increasing age was independently associated with reduced bladder contractility (measured by the $\mathrm{BCI}$ ), increasing degree of obstruction (measured by the BOOI), and increasing odds of finding a storage abnormality (detrusor overactivity, reduced compliance $<20 \mathrm{~mL}$ per $\mathrm{cm} \mathrm{H}_{2} 0$, or both). Although not strictly linear, for each 10 years increase in age, on average, the BCI fell 2.4 points and the BOOI increased by 2.4 points. Increasing decadal age was also negatively associated with capacity and positively associated with storage abnormality and PVR. 
TABLE 2.

Association between presence of storage abnormality and "age by decade"

\begin{tabular}{|c|c|c|c|c|c|c|c|c|}
\hline & \multicolumn{8}{|c|}{ Age by decade (years) and number of men with or without a storage abnormality } \\
\hline Storage Abnormality & $\mathbf{1 8 - 3 0}$ & $\mathbf{3 0 - 4 0}$ & $\mathbf{4 0 - 5 0}$ & $\mathbf{5 0 - 6 0}$ & $\mathbf{6 0 - 7 0}$ & $\mathbf{7 0 - 8 0}$ & $\mathbf{2 0 0}$ & Total \\
\hline No Storage Abnormality & 198 & 148 & 155 & 188 & 163 & 68 & 11 & 931 \\
\hline Abnormal storage & 119 & 94 & 71 & 102 & 154 & 108 & 17 & 665 \\
\hline Abnormal, \% & 37.5 & 38.8 & 31.4 & 35.2 & 48.6 & 61.4 & 60.7 & 41.7 \\
\hline Total & 317 & 242 & 226 & 290 & 317 & 176 & 28 & 1596 \\
\hline
\end{tabular}

Storage abnormality defined as detrusor overactivity, poor compliance $\left(20 \mathrm{~cm} \mathrm{H}_{2} 0\right)$, or both

The median BCI in adult men was noted to be about 100 in this study, which is similar to the findings of several other studies[7-9]. Underactivity was noted in $52.3 \%$, higher than the $11 \%$ to $40 \%$ reported in a review[10]. There was an independent age-associated decline in contractility. Literature on the association of age and bladder contractility is conflicting[11], but others studies have reported a similar association with age $[7,8,12]$. Age can impact bladder contractility by several possible mechanisms. These include changes in both afferent and efferent neuronal pathways as well as the smooth muscle and collagen within the bladder wall that might be mediated, at least in part, by ischemia[1]. While it is tempting to attribute all these changes simply to aging, it is often difficult to resolve whether the observations are due to disease processes that are increasingly common with aging. Older men are also more likely to suffer from diabetes. However, diabetes mellitus was not independently associated with underactivity in our patients $(n=498 ; 31.2 \%)$ when controlled for age. Lack of data on duration or control might have blunted our ability to identify its impact.

Bladder outlet obstruction was noted in $45.4 \%$ of our patients with median BOOI 37 (IQR 18 to 64) similar to the findings of Rosier et al. (BOOI 37)[12] but somewhat lower than that reported by Oelke et al. (BOOI 44) [9]. Equivocal obstruction was noted in a further 428 $(26.8 \%)$ of men. Age was independently associated with the possibility of finding obstruction, which is not surprising, given that age is associated with prostate size. However, it is instructive to note that a significant minority of patients showed no obstruction at all.

Presence of a storage abnormality (detrusor overactivity, poor compliance $<20 \mathrm{~mL}$ per $\mathrm{cm} \mathrm{H}_{2} 0$, or both) was associated with age. Both detrusor overactivity and poor compliance were noted to be more common in the elderly, although the latter was not statistically significant (Table 1). Overall detrusor overactivity and poor compliance were noted in $32.8 \%$ and $19.1 \%$, respectively. On multiple regression, presence of bladder outlet obstruction was independently associated with presence of a storage abnormality. In a study of 3357 men, detrusor overactivity and poor compliance was noted in $45 \%$ and $7.7 \%$, respectively [7]. An association between poor bladder compliance $\left(<20 \mathrm{~mL} / \mathrm{cm} \mathrm{H}_{2} 0\right)$ and older age, with a linear reduction for each decade beyond the sixth has been noted in another study[13]. Alterations in afferent signaling systems and connective tissue matrix are important in the pathogenesis of detrusor overactivity and reduced compliance that are often seen with aging[14]. These changes might be accelerated by the presence of concomitant obstruction[15].

Post hoc analyses of differences based on "age by decade" showed interesting sub-trends. The proportion of men with a strong detrusor dropped progressively with age from the sixth decade (Figure 1). The proportion of men with a storage abnormality showed a progressive increase beyond the age of 60 years, being $35.2 \%, 48.6 \%, 61.4 \%$, and $60.8 \%$ in the sixth, seventh, eighth and beyond eighth decade, respectively (Table 2).

Men under 30 years of age undergoing urodynamics were the least likely of any age group to show obstruction (30.3\%; median BOOI 26), with an additional $28.7 \%$ demonstrating equivocal obstruction (BOOI 20 to 40$)$. Underactive detrusor was noted in $54.6 \%$. Other authors examining young men with refractory urinary symptoms with urodynamics have reported different findings. A study of 86 men below the age of 45 years found obstruction in $62 \%$ and an underactive detrusor in $10 \%[16]$. This study, however, did not provide the data for men under 30 years separately[16]. Rosier et al. found a progressive reduction in detrusor contractility, as measured by the Watt factor, from the second decade to the ninth decade[12]. Young men might demonstrate the residual consequences of childhood disorders of lower urinary tract function, such as dysfunctional voiding, 
faulty toilet training, or bowel-bladder dysfunction. Of note, dysfunctional voiding is a common diagnosis in young men with refractory urinary symptoms undergoing urodynamics $[17,18]$.

Maximum flow rate and bladder capacity showed a reduction with age, but although statistically significant, this was not clinically relevant. However, a concomitant increase in residual urine implied progressive reduction in voiding efficiency with age. In fact, the effective capacity reduced by about one-third in men above 80 years of age compared with those between 18 and 30 years. This has implications for storage symptoms such as frequency and nocturia.

The European Association of Urology guidelines recommend use of preoperative urodynamics testing before surgery in men above 80 and below 50 years of age with predominant voiding symptoms (both weak recommendations), while acknowledging the lack of adequate data to support this guidance[4]. Our study would suggest that such evaluation might be particularly important in men under 30 years of age. Older men show a higher prevalence of storage disorders, underactivity, and obstruction, but the trends are gradual and noticeable well before the threshold of 80 years. Of note, men above the age of 80 years made up only $1.8 \%$ of our study population. While universal use of urodynamics has not been shown to improve patient outcomes, it is important to define subsets of men who might be at higher risk of non-obstructive lower urinary tract symptoms [19]. Such men might be less likely to have a satisfactory outcome after outlet surgery[2].

An important limitation of this study is the lack of clinical information with respect to symptoms. The method of recording symptoms varied during the study period, making it difficult to unify data. Hence, it is important to understand the clinical context for this group. Patients were typically offered urodynamics only when they failed medical management. A total of $17.2 \%$ had hydronephrosis of at least one kidney at presentation consistent with the refractory nature of their symptoms. Men with isolated storage abnormality were seldom subjected to urodynamics. Instead, they received treatment based on clinical judgment. Consequently, only $5.4 \%$ of men had an isolated storage abnormality. However, as we have reported earlier, presence of storage phase abnormality was associated with an increased probability of finding hydronephrosis[20]. The duration of symptoms might have impacted bladder function. In a study of men with and without outlet obstruction, BCI and flow rate reduced, while PVR increased over a follow-up of 10 years[21]. However, an earlier publication failed to show any change in detrusor contractility with time[22], and symptoms are not generally regarded as a reliable predictor of the underlying abnormality[23].

The policy with respect to surgery in men with a clinical diagnosis of bladder outlet obstruction would be expected to impact the findings of this (and similar studies). While elderly men often undergo surgical intervention without urodynamics this is unlikely to happen in young men. Therefore, the data for elderly men are likely to omit men with unequivocal clinical findings suggestive of benign prostatic obstruction (who might be expected to have a higher BOOI and BCI). Of note, the bias introduced by this is likely to strengthen the significance of the lower propensity for finding obstruction that we noted in men less than 30 years of age.

This database study examined urodynamics findings across the entire spectrum of adult men. While a few studies have provided these data, most studies have excluded either the young or the elderly.[7,9,24,25]

\section{Conclusions}

Examining all men in a single study offers the opportunity to apply a uniform yardstick to yield comparative data. The conclusions from this study are clearly not applicable to the general population of adult men. However, they give a clue to anticipated lower urinary tract function in adult men with refractory lower urinary tract symptoms in whom a urodynamic evaluation (and by extension a possible surgical intervention) is being contemplated. 


\section{References}

1. Vahabi B, Wagg AS, Rosier PFWM, Rademakers KLJ, Denys M-A, Pontari $\mathrm{M}$, et al. Can we define and characterize the aging lower urinary tract?-ICI-RS 2015. Neurourol Urodyn.2017;36:854-858. DOI: 10.1002/nau.23035

2. Zhong P, Zhao YR, Qiao BM, Yang F-J, Zhu Y, Yang Z-Q, et al. Comparison of two numerical parameters to assess detrusor contractility in prognosing short-term outcome after transurethral resection of the prostate. Urol Int.2020;104:361-366. D0I: 10.1159/000503331

3. Antunes AA, Iscaife A, Reis ST, Albertini A, Nunes MA, Lucon AM, et al. Can we predict which patients will experience resolution of detrusor overactivity after transurethral resection of the prostate? J Urol.2015;193:2028-2032. DOI: 10.1016/j.juro.2014.12.095

4. Gravas S, Cornu JN, Gacci C, Gratzke C, Herrmann TRW, Mamoulakis $C$, et al. Managment of non-neurogenic male lower urinary tract symptoms. European Association of Urology Guidelines, 2020. Available at: https://uroweb.org/guideline/treatment-of-nonneurogenic-male-luts. Accessed December 15, 2020

5. Rosier PFWM, Schaefer W, Lose G, Goldman HB, Guralnick M, Eustice $S$, et al. International continence society good urodynamic practices and terms 2016: urodynamics, uroflowmetry, cystometry, and pressure-flow study. Neurourol Urodyn.2017;36:1243-1260. DOI: 10.1002/nau.23124

6. Abrams P. Bladder outlet obstruction index, bladder contractility index and bladder voiding efficiency: Three simple indices to define bladder voiding function. BJU Int.1999;84:14-15. doi: 10.1046/j.1464410x.1999.00121.x

7. Jeong SJ, Lee JK, Kim KM, Kook H, Cho SY, Oh S-J. How do we diagnose detrusor underactivity? Comparison of diagnostic criteria based on an urodynamic measure. Investig Clin Urol.2017;58: 247-254. doi: 10.4111/icu.2017.58.4.247

8. Namitome R, Takei M, Takahashi R, Kikutake C, Yokomizo A, Yamaguchi 0 , et al. A prediction model of detrusor underactivity based on symptoms and noninvasive test parameters in men with lower urinary tract symptoms: an analysis of a large group of patients undergoing pressure-flow studies. J Urol.2020;203:779-785. D0I: 10.1097/ JU.0000000000000616

9. Oelke M, Rademakers KLJ, van Koeveringe GA. Unravelling detrusor underactivity: development of a bladder outlet resistance-bladder contractility nomogram for adult male patients with lower urinary tract symptoms. Neurourol Urodyn.2016;35:980-986. doi: 10.1002/ nau. 22841

10. Jeong SJ, Kim HJ, Lee YJ, Lee JK, Lee BK, Choo YM, et al. Prevalence and clinical features of detrusor underactivity among elderly with lower urinary tract symptoms: a comparison between men and women. Korean J Urol.2012;53:342-8. doi: 10.4111/kju.2012.53.5.342
11. Beltrame F, Ferreira FT, Lorenzetti F, Dambros M, Bisogni S, Dambros M. Bladder function in obstructed men - does age matter? Aging Male.2015;18:143-148. doi: 10.3109/13685538.2015.1025377

12. Rosier PFWM, Ten Donkelaar CS, de Kort LMO. Clinical epidemiology: detrusor voiding contraction maximum power, related to ageing. Urology.2019;124:72-77. doi: 10.1016/j.urology.2018.10.038

13. Madersbacher S, Pycha A, Klingler CH, Mian C, Djavan B, Stulnig T, et al. Interrelationships of bladder compliance with age, detrusor instability, and obstruction in elderly men with lower urinary tract symptoms. Neurourol Urodyn.1999;18:3-15. doi: 10.1002/ (sici)1520-6777(1999)18:1<3:.:aid-nau2>3.0.c0;2-4

14. Bellucci CHS, Ribeiro W de 0, de Bessa J Jr, Antunes AA, Leite $\mathrm{KMR}$, et al. Increased detrusor collagen is associated with detrusor overactivity and decreased bladder compliance in men with benign prostatic obstruction. Prostate Int.2017;5:70-74. D0I: 10.1016/j. prnil.2017.01.008

15. Oelke M, Baard J, Wijkstra H, de la Rosette JJ, Jonas U, Höfner K. Age and bladder outlet obstruction are independently associated with detrusor overactivity in patients with benign prostatic hyperplasia. Eur Urol.2008;54:419-426.

16. Nitti VW, Lefkowitz G, Ficazzola M, Dixon CM. Lower urinary tract symptoms in young men: Videourodynamic findings and correlation with noninvasive measures. J Urol.2002; 168: 135-8.

17. Kaplan SA, Ikeguchi EF, Santarosa RP, D'Alisera PM, Hendricks J, Te $A E$, et al. Etiology of voiding dysfunction in men less than 50 years of age. Urology.1996;47:836-839. DOl: 10.1016/S0090-4295(96)00038-6

18. Wang CC, Yang SSD, Chen YT, Hsieh JH. Videourodynamics identifies the causes of young men with lower urinary tract symptoms and low uroflow. Eur Urol.2003;43:386-390.

19. Drake MJ, Lewis AL, Young GJ, Abrams P, Blair PS, Chapple C, et al. Diagnostic assessment of lower urinary tract symptoms in men considering prostate surgery: a noninferiority randomised controlled trial of urodynamics in 26 hospitals. Eur Urol.2020;78:701-710. DOI: 10.1016/j.eururo.2020.06.004

20. Sinha S, Matai L. Is isolated bladder outlet obstruction associated with hydronephrosis? A database analysis. Neurourol Urodyn.2020;39:2361-2367.

21. Chen SF, Lee $\mathrm{CL}$, Kuo HC. Change of detrusor contractility in patients with and without bladder outlet obstruction at ten or more years of follow-up. Sci Rep.2019;9. doi:10.1038/s41598-019-55386-2.

22. Thomas AW, Cannon A, Bartleh E, Ellis-Jones J, Abrams P. The natural history of lower urinary tract dysfunction in men: minimum 10-year urodynamic follow-up of untreated detrusor underactivity. BJU Int.2005;96:1295-1300. 
23. Ding YY, Lieu PK, Choo PWJ. Is the bladder "an unreliable witness" in elderly males with persistent lower urinary tract symptoms? Geriatr Nephrol Urol.1997;7:17-21. doi: 10.1023/a:1008299528728

24. Karami H, Valipour R, Lotfi B, Mokhtarpour H, Razi A. Urodynamic findings in young men with chronic lower urinary tract symptoms. Neurourol Urodyn.2011;30:1580-1585. doi: 10.1002/nau.21095

25. Jamzadeh AE, Xie D, Laudano M, Seklehner S, Elterman DS, Shtromvaser $L$, et al. Urodynamic characterization of lower urinary tract symptoms in men less than 40 years of age. World $\mathrm{J}$ Urol. 2014;32:469-473. DOI: 10.1007/s00345-013-1134-z 